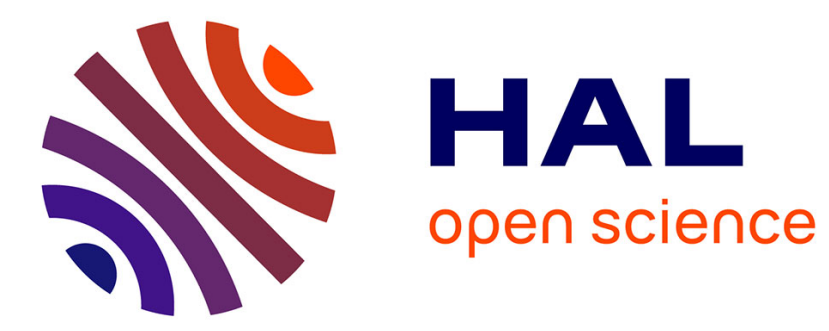

\title{
X-ray lithography : an overview and recent activities at super-ACO
}

\author{
F. Rousseaux, A. Haghiri-Gosnet, Y. Chen, M. Ravet, H. Launois
}

\section{To cite this version:}

F. Rousseaux, A. Haghiri-Gosnet, Y. Chen, M. Ravet, H. Launois. X-ray lithography: an overview and recent activities at super-ACO. Journal de Physique IV Proceedings, 1994, 04 (C9), pp.C9-237C9-244. 10.1051/jp4:1994942 . jpa-00253503

\section{HAL Id: jpa-00253503 https://hal.science/jpa-00253503}

Submitted on 1 Jan 1994

HAL is a multi-disciplinary open access archive for the deposit and dissemination of scientific research documents, whether they are published or not. The documents may come from teaching and research institutions in France or abroad, or from public or private research centers.
L'archive ouverte pluridisciplinaire HAL, est destinée au dépôt et à la diffusion de documents scientifiques de niveau recherche, publiés ou non, émanant des établissements d'enseignement et de recherche français ou étrangers, des laboratoires publics ou privés. 


\title{
X-ray lithography: an overview and recent activities at super-ACO
}

\author{
F. Rousseaux, A.M. Haghiri-Gosnet, Y. Chen, M.F. Ravet and H. Launois \\ Laboratoire de Microstructures et de Microélectronique, L2M/CNRS, 196 avenue Henri Ravera, \\ 92225 Bagneux cedex, France
}

\begin{abstract}
Résumé: Dans ce papier, nous présentons les possibilités de la lithographie $X$ par proximité (XRL) pour la production de circuits imprimés à très forte intégration (ULSI). Les dernières performances, réalisées en utilisant le rayonnement synchrotron, montrent que cette technologie est prête à aborder l'échelle d'intégration du Gbit. Nous décrivons également l'activité du laboratoire L2M/CNRS qui comprend le développement d'une technologie pour réaliser des nano-masques $(<0.1 \mu \mathrm{m})$ et la réalisation d'expériences de nano-lithographie X sur Super-ACO. La description des résultats obtenus est une démonstration des possibilités offertes par cette technique en micro et nano-fabrication .

Abstract: In this paper, the current status of synchrotron based XRL is discussed in view to present this technic as an alternative path to ultra-large-scale-integrated circuit (ULSI) with feature sizes of quarter micrometer and below. Also, are described the L2M laboratory activities in nanomask fabrication and nanolithography using the synchrotron radiation of Super-ACO. Results show that the range of $50 \mathrm{~nm}$ can be currently achieved. Examples of device nano-fabrication are given.
\end{abstract}

\section{Introduction}

During the last 20 years, miniaturization has continuously been in progress. The main forces driving the demands were the science push of novel physics and the market of small electronics devices. This development of microtechnology was enabled by the continuous advances realized in lithography which is the first step indispensable in device or circuit fabrications. As far as now, ultimate limits in lithography are not achieved, and many lithography technics are still under progresses. Among them, Xray lithography using synchrotron radiation has proved to be a valuable technic for the production of sub-micron microstructures and can sustain comparison with deep-UV lithography and e-beam lithography regarding resolution, wafer throughput and process latitude.

This paper adresses the state-of-the-art of X-ray lithography as well as industry efforts to develop commercial systems. The work conducted at L2M laboratory in this field is also described. This work includes high resolution $x$-ray mask realizations, modelling, and studies of the lithographic performances using an advanced alignment system implemented at super-ACO storage ring. Recent L2M results obtained in the range of $250 \mathrm{~nm}$ to $50 \mathrm{~nm}$ feature sizes are reported and will demonstrate the applicability of $\mathrm{X}$-ray lithography to microfabrication and nanofabrication.

In this paper, we mainly focuse on $\mathrm{X}$-ray proximity lithography (XRL) which is the most advanced technic in $R \& D$ applications. Another scheme called "soft $\mathrm{X}$-ray projection lithography " should be only considered in a far future.

\section{Ultimate limits of X-ray lithography}

In XRL, a mask with a patterned absorber is placed in a close proximity $(<50 \mu \mathrm{m})$ to a resistcoated substrate. X-rays are shone through the mask and expose the resist in the clear areas. Resolution is essentially limited by two factors: diffraction and photoelectron-induced spreading. 


\subsection{Diffraction}

The proximity image formation can be described using diffraction theory in the near-field region. In a first approach, the resolution is defined as the minimum resolved period $\left(\mathrm{p}_{\min }\right)$ of a grating which can be printed in a proximity distance (s) [1]. It is shown that (when $\lambda \ll<\operatorname{pmin}$ ) :

$$
\mathrm{p}_{\min }=\mathrm{K}(\lambda s)^{1 / 2}
$$

where $\lambda$ is the illuminating wavelength and $\mathrm{K}$ a process related constant which varies between 1 to 2.5 . and is gap-dependent. Relation (1) shows that better resolution is achieved with smaller gaps and shorter wavelengths. At the limits, if mask and wafer are closely in contact, the diffraction effect is eliminated and resolution is only determined by the photon-induced effect in the resist. In that case X-ray lithography resolution should reach a few nanometers as shown below. This has not yet experimentally been proved because of the difficulty to realize such small patterns on a mask.

If one considers conditions more realistic for a mass production system, a given distance between mask and wafer is more desirable. If $\mathrm{K}$ is taken as 1.6 as generally [2], $\lambda$ is $8 \AA$ (typical of a synchrotron source) and the mask-to-wafer gap is $10 \mu \mathrm{m}$, then, the minimum resolved period is $0.14 \mu \mathrm{m}$.

Accurate models based on the Rayleigh-Sommerfeld diffraction formula have recently been developed and allow to predict with accuracy the lithographic performances of a given system. Complete calculations of the diffraction intensity taking into account all the relevant physical effects that may play a role in the image formation are used and provide a good agreement with the available experimental results [3-5]. In this approach, are included the effects of the source spectrum, source spatial coherence, beamline or condensing system, absorption-mask propagation, absorber diffraction, mask linewidth bias, gap diffraction and resist absorption. From these new simulations have merged recommandations to improve the image quality. The most determining are:

- some degree of incoherence in the source should be desirable. Synchrotron radiation source has a small spatial extension. Typically the angle subtended by the source is of the order of $10^{-4} \mathrm{rad}$. Different methods have been proposed to increase the penumbral blur and the partial spatial coherence in synchrotron sources: tilting the mask and the wafer with respect to the source during exposure, or induce vibration of the mask and the wafer. Experiments have shown enhancement of aerial images.

- the quality of aerial images depends strongly on the phase shift and attenuation in the absorber. It was found that a thinner absorber should provide a better image than a thicker, more absorbing one [2][3]. A lower contrast will provide a stronger interference between the fields in the geometrical shadow region, yielding an even better image. Proximity imaging can thus be strongly enhanced by controlling the phase behavior though the absorber, opening the possibility of extending XRL well into the sub- $0.1 \mu \mathrm{m}$ range. Figure 1 illustrates the influence of the absorber thickness for a broad band synchrotron beam. These simulations calculated using the L2M code show that the image contrast is enhanced when the absorber thickness is reduced down to $300 \mathrm{~nm}$. Calculations take into account of the Super-ACO spectral distribution and of the L2M mask characteristics (W absorber, SiC membrane). They correspond to the absorbed dose distribution in PMMA of a grating 50/50 nm line \& space at a gap $5 \mu \mathrm{m}$.

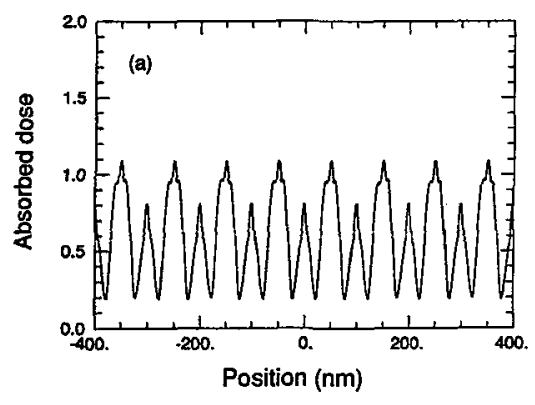

Fig.1a: Absorbed dose distribution with $450 \mathrm{~nm}$ thick-tungsten.

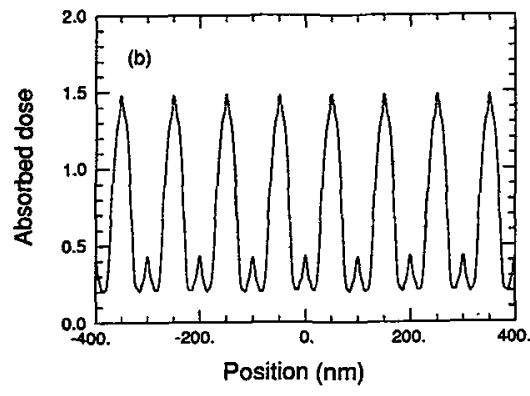

Fig.1b: Absorbed dose distribution with $300 \mathrm{~nm}$ thick-tungsten 


\subsection{Photo-electron processes}

In the range of X-ray energies useful for lithography, inelastic (or Compton) interaction between the incident photon and the absorbing medium are unlikely. A single photon is absorbed by an atom giving rise to a relatively high-energy photoelecton and secondary electrons. In low-Z materials like carbon and oxygen, a considerable amount of energy is deposited in the resist through Auger processes [6][7]. It was recently shown that while high-energy secondaries do exist, the Auger processes tend to weight the mean of the energy distribution toward low energies [8], minimizing the extension of exposed area about the incident trajectory. As a result, $30 \mathrm{~nm}$ lines were easily resolved [9] using X-ray beam with photon energies as high as $1.49 \mathrm{KeV}$ (the $\mathrm{Al} \mathrm{K}$ emission series) demonstrating that the blur induced by photoelectron processes should be less than $5 \mathrm{~nm}$.

\subsection{Conclusion}

From these overall considerations, it appears that resolution can be extended well down $100 \mathrm{~nm}$. The ultimate limits of resolution for XRL are not yet achieved. The best example is $17.5 \mathrm{~nm}$ lines and spaces obtained by contact [10]. Then, X-ray proximity lithography is suitable (both from the point of resolution process latitude and from fundamental principles) for $0.1 \mu \mathrm{m}$ minimum feature size projects. This makes $\mathrm{x}$-ray lithography applicable to gigabit DRAM device fabrication.

\section{X-ray proximity lithography system}

If we consider X-ray proximity lithography as a complete system, resolution and process latitude in resist exposure are not the only elements determining the applicability of the technic. Other critical issues evolve from consideration of the wavelength, X-ray source, mask-making, resist behavior and alignment systems. Research groups and major companies have developed intense activities to resolve these different challenges and can propose practical solutions. National programs in USA (DALP, SEMATECH) and in Japan (through MITI organization) are supporting R\&D activities because they are considering XRL as the primary alternative to optics for the deep-submicron device processing.

New chemically amplified resists which meet the XRL requirements of high sensitivity (30-100 $\left.\mathrm{mJ} / \mathrm{cm}^{2}\right)$ and high resolution $(0.1 \mu \mathrm{m})$ are commercially available [11][12]. X-ray steppers are also manufactured with overlay performance $3 \sigma=70-90 \mathrm{~nm}$ [13][14] and have been used for device fabrication. High performance $512-\mathrm{Kb}$ SRAMs in a $0.25 \mu \mathrm{m}$ CMOS technology have been fabricated by IBM [15]. NTT program is also aimed at $0.25 \mu \mathrm{m}$ CMOS [16] and L2M has succeeded in the realisation of a fully functional $0.150 \mu \mathrm{m}$ gate-length HEMTs [17] .

Nevertheless mask technology remains the key point to insure XRL complete success. It has been considerably improved in the last decade, but further improvements are still necessary. In this section, we will only focuse on X-ray source developments and mask technology.

\subsection{Optimized wavelength}

The exposing wavelength must be compatible with a relative good absorption in a resist film (i.e, $10-50 \%$ in $1 \mu \mathrm{m}$ thickness), minimized diffraction effects and easy mask technology. This last task, implies reasonable transmission through the mask membrane (i.e. 50-90\%) and reasonable attenuation in an absorber for a film thickness no thicker than about 4 times the minimum feature size. These requirements fix the wavelength range to between 0.8 and $1.5 \mathrm{~nm}$.

\subsection{X-ray sources}

Two types of $\mathrm{x}$-ray sources meet XRL requirements. They are: synchrotron sources and laserplasma sources. Both have a small size $(100-200 \mu \mathrm{m})$.

Synchrotron radiation represents the ideal source because of its properties of collimation, high flux and tunable spectral distribution. These properties guarantees high aspect ratio and high resolution, high throughput and low cost per wafer exposure. The main drawback of these sources are their high investment cost. They are thus attractive for very large volume production. Small "compact" storage rings, utilizing superconducting magnets, have been developed and are in use for R\&D. The "racetrack" 
design (Fig 2), represents the optimized solution relative to a minimum covered area, a maximum number of beam lines, an easy procedure to inject particles, an excellent beam lifetime. Most of the compact rings (five) have been fabricated in Japan by major companies like NTT, Mitsubishi, Sumitomo [18-19] and are currently used. One is operating at IBM Fishkill plant [20] in USA and was constructed by Oxford Instruments [21]. In addition, many national X-ray facilities offer dedicated beam lines for X-ray activities: USA, France, Germany, England, Japan and China. New projects are also planned in USA, Sweeden, Italy, Germany, Corea, and Taïwan.

Laser-plasma sources constitute an interesting alternative adapted to smaller productions because a stepper can be associated with the source resulting in a granular module like in optical lithography. In this case, the X-ray radiation is emitted by a hot plasma generated by laser beams. However high conversion efficiencies, in a given spectral range, can only be achieved under specific plasma conditions. This leads to some restrictions in possible target materials and irradiation conditions (laser wavelength, laser intensity, pulse duration). Today, these sources remain an hundred times less powerful than synchrotron sources, that is not sufficient for practical applications. In addition, one has to be concerned with debris ejected from the plasma.sources. However, intense efforts are made in this field, particularly in USA and Canada. Recently, Hampshire Instruments has failed in the commercialization of a source coupled with an $\mathbf{x}$-ray stepper [22], but efforts are still continuing.

\subsection{Mask technology}

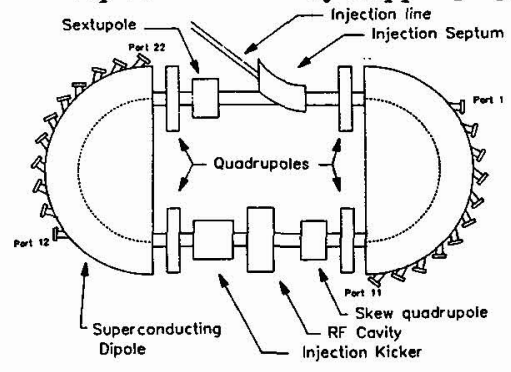

Figure 2

"racetrack" compact ring schematic [20]

The main challenge for XRL is the mask technology because X-ray mask are "1X". This means that patterns on the mask must be the same size as the image and thus, the precision of the mask becomes critical. Precision is mainly dependent on the choice of the materials elements and on the severe control of their properties. It requires also the optimizing of the e-beam patterning and the pattern transfer. Unlike optical masks, X-ray masks can be used as masters for the generation of working masks that constitutes a precious counterpart.

An Xray mask consists in a transparent flat membrane supporting opaque absorber structures (Fig.3). Membranes are formed by the deposition or growth on a silicon wafer. In the range of the spectral distribution 0.8 to $1.5 \mathrm{~nm}$, membrane materials have to be choosen among ligth atomic weight elements. Thickness must not exceed a few microns $(<3 \mu \mathrm{m})$ in order to get X-ray transmission better than $50 \%$. X-ray membranes have to meet a number of relevant properties: mechanically one desires the membrane to lie flat and be robust to mask fabrication processing and mask handling. The membrane stress has to be tensile to avoid out-plane distortion while a high fracture strength has to be preserved. High stiffness is required for avoiding in-plane distortion while supporting an absorber. Stability under irradiation, large thermal conductivity, low thermal expansion coefficient and visible optical transparency are also key parameters. Roughness must also be lower than the wavelength of the light used for optical alignments on steppers for limiting the scattering and must be compatible with the size of the absorbing structures.
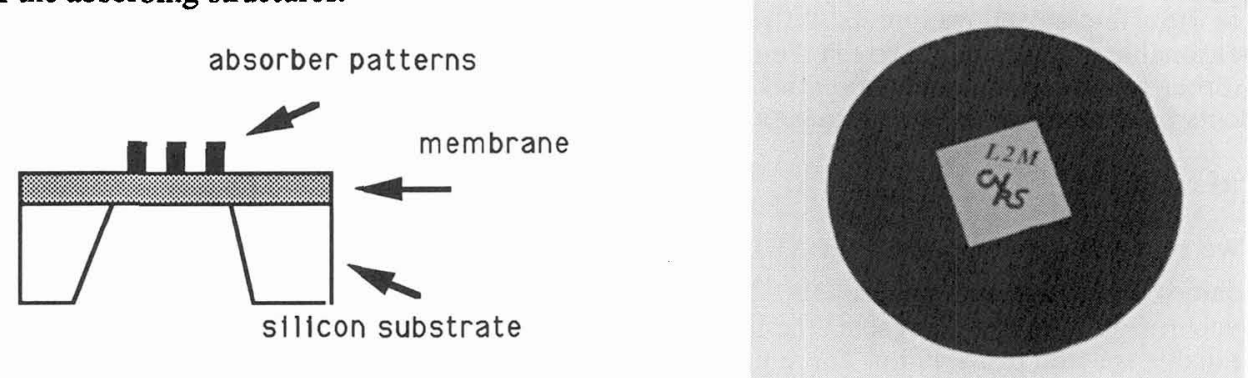

Fig.3: X-ray mask scheme

Fig.4: L2M-SiC:H PECVD membrane $\left(30 \times 30 \mathrm{~mm}^{2}\right)$ 
Many materials have been studied during the last decade, boron nitride (BNx), boron doped silicon (B doped $\mathrm{Si})$, silicon carbide $(\mathrm{SiC})$, silicon nitride $\left(\mathrm{SiN}_{\mathrm{X}}\right)$ and diamond. Figures of merit have been elaborated which conclude that $\mathrm{SiC}$ and diamond are the best materials for future $\mathrm{X}$-ray membrane application [23]. This result is particularly due to their high nominal Young's modulus. However improvements of uniformity of thickness, surface roughness and optical transmissivities still remain to be achieved. Both materials are under active study for production mask membranes. Today, B doped Si [24] are the most widely used in United States, while SiNx is the current standard in Japan [25]. In L2M laboratory, SiC:H membranes are currently manufactured [26] (Fig. 4) and diamond is investigated[27].

The absorber is a high atomic weight material. $\mathrm{Au}, \mathrm{W}$ and $\mathrm{Ta}$ are the most currently used. $\mathrm{Au}$ is associated with an additive electroplating process transfer (gold growth in the resist mold) while W and Ta are dry etchable and as refractory materials are more stable than gold. In the spectral range used in XRL, absorber thickness is adjusted from $0.3 \mu \mathrm{m}$ to $0.7 \mu \mathrm{m}$, depending on the application. For all materials, stresses have to be minimized. Stresses moving into the range $10^{7}-5 \times 10^{8}$ dynes $/ \mathrm{cm}^{2}$ corresponding to in plane distortion well below $10 \mathrm{~nm}$ is more than adequate for $0,1 \mu \mathrm{m}$ ULSI, such range of stresses can be controlled. Pattern transfer technologies in the absorber have extensively been studied. Advanced reactive dry etching methods (RIE) associated with backside cooling allow to achieve high resolution pattern transfer into the absorber layers .

Mask patterning is realized by a focused electron-beam system (EBL). The resolution is determined by the electron probe size and by the interaction of the beam with resist and/or mask absorber materials. Spot size is rarely a limiting factor in electron-beam resolution while electron backscattering limits the latitude and the robutness of the EBL process and makes dimensional control difficult especially over high-Z substrates as $W$. To improve resolution one has to use high energy electrons ( $50 \mathrm{KeV}$ to $100 \mathrm{KeV}$ ), light atomic weight substrate (thin membranes) and thin resist layer. Current resolution of $0.1 \mu \mathrm{m}$ patterns are regularly produced in resist. The second important issue of EBL systems is to provide sufficient overlay. Current pattern generators cannot locate pattern with a sufficient precision for ULSI $(0.1 \mu \mathrm{m})$ general-purpose circuits, in part because of distortion within the scan fields, and in part because of column and interferometer stage drift (thermal, mechanical, electrostatic, magnetic, electronic,etc...). Different strategies are proposed to overcome this problem, they are still under evaluation and not commercially available.

\subsection{Conclusion}

Clear progresses in mask fabrication have been made, particularly in the area of relevant mask materials and technology processes. The next challenges should be to achieve zero defect mask fabrication and to develop mask inspection and repair. Recently, the KLA corporation has produced two tools suitable for application to sub-half-micrometer X-ray mask inspection and a Micrion repair tool can read the KLA defect inspection report, locate the defect on the mask and repair it. Defects smaller than

$0.05 \mu \mathrm{m}$ can currently be repaired through ion etching or through ion-induced deposition processes.For the near future, pattern placement accuracy in the e-beam tools as well as alignment accuracy for steppers must be improved to achieve $0.1 \mu \mathrm{m}$ ULSI. Such problems are, of course, common to all forms of lithography. Experimental demonstrations have shown that X-ray lithography system could define $0.25 \mu \mathrm{m}$ patterns in a production environment with a yield that promises to be better than that of optical systems. Moreover, it is extendable in manufacturing at least down to $50 \mathrm{~nm}$ minimum features.
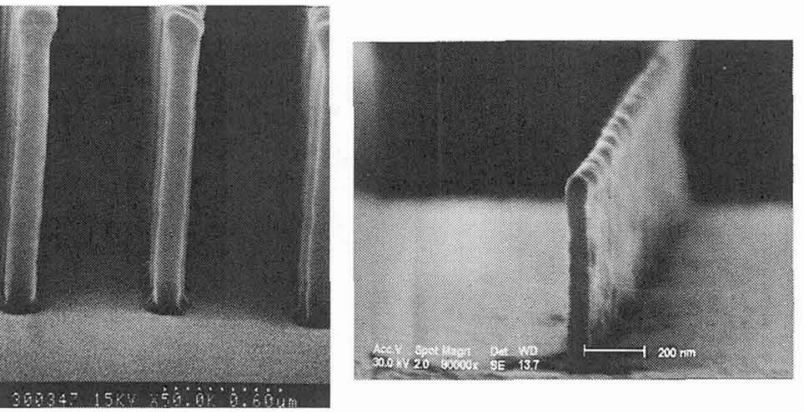

$60 \mathrm{~nm}$ linewidth

$0.13 \mu \mathrm{m}$ linewidth $1.6 \mu \mathrm{m}$ resist height

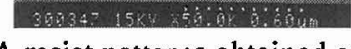

Fig. 5: PMMA resist patterns obtained at L2M facility (Super-ACO) with a gap $<10 \mu \mathrm{m}$. 
Additional basic advantages of XRL should be underlined: XRL enjoys absence of scattering at the various interfaces, large depth-of-focus $(10-50 \mu \mathrm{m})$. Aspect ratios in thick resist are excellent (Fig. 5) . Resist patterns with vertical sidewalls are obtained by simple process with a precise feature size and line edge control. Results are independent of substrate topography, of substrate reflectivity, of pattern geometry, there are no proximity effects, the process is insensitive to dust and contamination,etc.

\section{L2M X-ray lithography activities and results}

XRL research activities have been developed in L2M laboratory since 1986 including X-ray mask fabrication. The main goal of our group consists in the search of the ultimate limits of resolution compatible with a R\&D lithographic system. As a consequence, we have developed an X-ray mask technology compatible with an advanced stepper (Karl Suss XRS 200) and implemented a lithography facility using synchrotron radiation at super-ACO storage ring.

\subsection{L2M X-ray mask characteristics}

$\mathrm{X}$-ray lithography performance using a commercial x-ray stepper depends to a large extent on the mask fabrication. Besides high resolution patterning, a number of additional requirements have to be met. Typically, the accepted flatness is less than $5 \mu \mathrm{m}$, the optical transparency should be more than $50 \%$ and the stability under x-ray irradiation should be at least $10^{5}$ exposures with a typical dose of 100 $\mathrm{mJ} / \mathrm{cm} 2$. To meet these requirements we have optimized a mask technology based essentially on silicon carbide (SiC) and tungsten (W) material processing.

\section{1.l Membranes}

SiC films are deposited on silicon substrates by $\mathrm{rf}$ low frequency glow discharge decomposition of silane $\left(\mathrm{SiH}_{4}\right)$ and methane $\left(\mathrm{CH}_{4}\right)$ (PECVD) without thermal assistance. The deposition parameters (power, radio-frequency (rf) and gaz proportions) have been optimized to obtain a stoechiometric composition. Structural analysis indicates that PECVD deposition results in an amorphous SiC:H material [28] that presents an excellent optical transparency. This property is due partly to the hydrogen content which saturates the dangling bonds and partly to the very small roughness $(<5 \mathrm{~nm})$. Stress adjustment $(+50 \mathrm{MPa} \pm 10)$ is obtained by a progressive thermal annealing up to $450^{\circ} \mathrm{C}$. Membranes $\left(30 \times 30 \mathrm{~mm}^{2}\right), 2 \mu \mathrm{m}$-thick, obtained by chemical back etching of the (4") Si wafer are currently fabricated and used on the stepper.

\subsubsection{Absorber deposition, patterning and tranfer}

In this section we only focuse on tungsten absorber technology which was found to be the optimal solution to achieve very high resolution x-ray masks. Tungsten is deposited on the SiC film by If magnetron sputtering with a choice of parameters compatible with stress minimized $( \pm 200 \mathrm{MPa})$ and a dense structure stable with time [29]. Afterwards, the absorber patterning is performed by e-beam lithography (EBL) with a JEOL 5D2U vector scan generator at $50 \mathrm{keV}$ beam energy. A single layer resist (PMMA) processing was optimized which gives a patterning resolution down to $40 \mathrm{~nm}$. The resist patterns are then transfered in the $W$ layer with an optimized reactive ion etching (RIE) processing at $\mathrm{T}=8^{\circ} \mathrm{C}$, based on $\mathrm{SF}_{6} / \mathrm{CHF}_{3}$ 1:4 mixture gases [26]. Nano mask-patterns have been obtained with this technology. Typically, gratings of $200 \mathrm{~nm}$ period and a minimum linewidth close to $50 \mathrm{~nm}$ with aspect ratio of 9 and quasi vertical sidewalls $\left( \pm 2^{\circ}\right.$ ) (Fig.6) are realized.

(a)

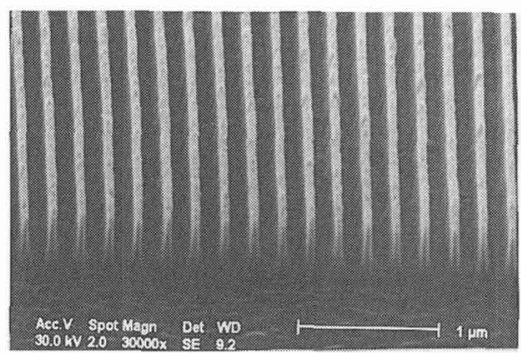

(b)

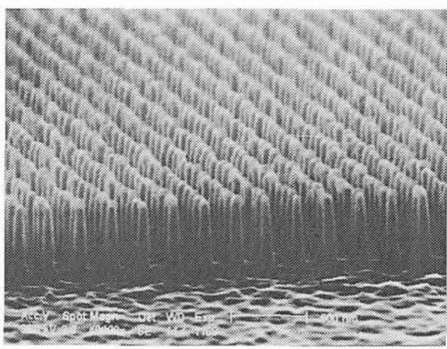

Fig. 6: L2M X-ray mask for nanolithography: (a) grating 50/150 nm, line \& space (L\&S), (b) dot matrix 50/150 nm L\&S. Patterns are etched in $450 \mathrm{~nm}$ W-thick. 


\subsection{XRL modelling tool}

The search of resolution limits requires the study of proximity image formation and exposure conditions. A simulation code has been developed at L2M [30] as a tool to study the XRL process latitude. This code includes the convolution of the polychromatic diffraction and takes into account the beam propagation through the mask absorber, the diffraction in mask-to-wafer gap space and the resist absorption. Lithography analysis based on the absorbed dose distribution is more relevant than that based on the diffraction intensity calculations. As we are mostly concerned by the replication of very small periodic gratings, we are more interested in the image contrast $\mathrm{C}_{\mathrm{d}}$, defined by the maximum $\left(\Delta_{\max }\right)$ and minimum $\left(\Delta_{\min }\right)$ values of the absorbed dose, i.e.,

$$
\mathrm{C}_{\mathrm{d}}=\left(\Delta_{\max }-\Delta_{\min }\right) /\left(\Delta_{\max }+\Delta_{\min }\right)
$$

Figure 7 gives two examples of such analysis. Image contrast has been examined as a function of the mask-to-wafer gap for mask gratings of $200 \mathrm{~nm}$ period and various linewidth $50 \mathrm{~nm}$ (Fig.7a) and 100 $\mathrm{nm}$ (Fig.7b). Clearly, a good contrast $(>0.5$ ) does exist close to a gap of $10 \mu \mathrm{m}$ for gratings of linewidth between $50 \mathrm{~nm}$ to $100 \mathrm{~nm}$. As predicted, this result illustrates the large exposure latitude of XRL.

(a)

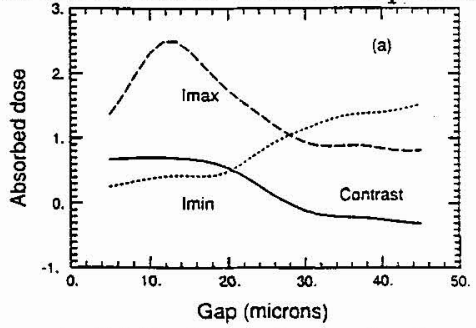

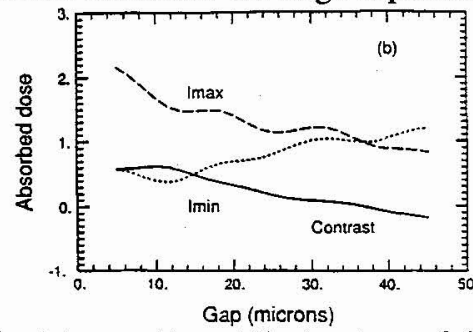

(b)

Fig. 7: Contrast (solid line), maximum (broken line) and minimum (dotted line) values of the absorbed dose distribution as a function of gap. Fig.7(a) grating $50 \mathrm{~nm} / 200 \mathrm{~nm}$. Fig. 7 (b) grating $100 \mathrm{~nm} / 200 \mathrm{~nm}$.

\subsection{Comparison with replication results}

Replications are made in the L2M lithography station installed at super-ACO (L.URE-Orsay) (Fig.8). With our present combination of the beam line, stepper (XRS200) and resist (PMMA) processing, all gratings of $200 \mathrm{~nm}$ period have been easily replicated at a gap $10 \mu \mathrm{m}$, giving a minimum linewidth of $50 \mathrm{~nm}$. Figure 9 shows the resist profile replicated with a dedicated dose at $2.5 \mathrm{~J} / \mathrm{cm} 2$ by a mask of grating of $200 \mathrm{~nm}$ period. Exposures at sub-10 $\mu \mathrm{m}(\geq 5 \mu \mathrm{m})$ were tested showing no significant improvement for the replication of the $200 \mathrm{~nm}$ period gratings. This result is consistent with our analysis based on the absorbed distribution and illustrates the large process latitude of XRL in a production environment. Better resolution can be obtained as predicted by our similations, it only depends on the availability of very small size mask-patterns. Gratings and dot matrix of higher density (period= $120,140,160 \mathrm{~nm}$ ) as well as isolated lines $(30-40 \mathrm{~nm})$ can be elaborated with our technology and should be replicated at a gap of $5-6 \mu \mathrm{m}$. This task is underway but the whole process has not yet been optimized.

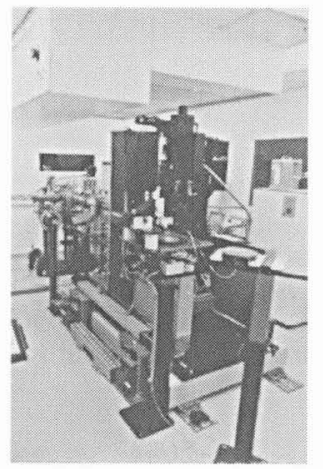

Fig.8: L2M XRL station at super-ACO

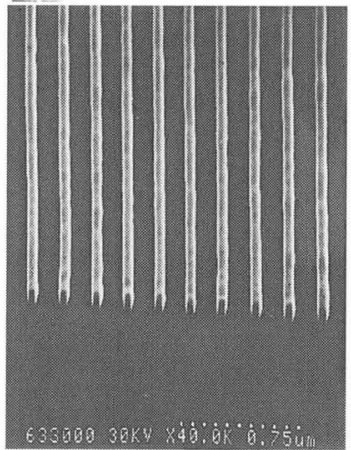

Fig. 9: SEM micrographs of the PMMA resist profile of a grating $50 / 150 \mathrm{~nm}$ (L\&S) 


\section{Conclusion}

XRL L2M activity meets the international level concerning X-ray mask technology and lithographic performances. Resolution performances in the range 100-50 nm, obtained at super-ACO, confirm what is today predicted for XRL and demonstrate the applicability of this technic to micro and nano-fabrication. These results have been used for the fabrication of both quantum wires and high speed devices. Combining our X-ray nanolithography with a selective implantation induced intermixing, quantum wires have been fabricated. Also, $150 \mathrm{~nm}$ gate-length HEMTs have been achieved using XRL for the five processing levels, as shown on figure 10. This transistor is based on III-V materials, i.e. planar doped GaAlAs/GaAs heterostructure [17].

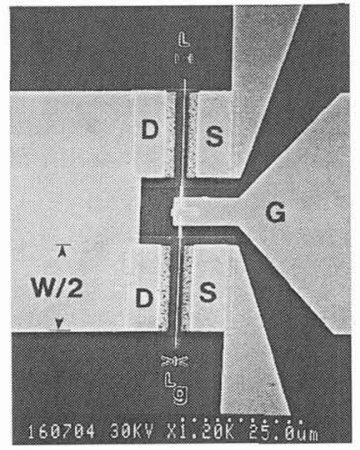

Fig.10: L2M: 150nm gate-length HEMT fabricated using syncrotron radiation at Super-ACO.

\section{References}

[1] M. Peckerar, J. Maldonado, Proceedings of the IEEE, vol. 81 n $^{\circ} 9$ (1993) 1249

[2] S.D.Hector, M.L.Schattenburg et al.J.Vac.Sci. Technol. B10 (6) (1992) 3164

[3] J.Z.Guo and F.Cerrina, J.Vac.Sci.Tecnol. B10 (6) (1992)

[4] M.L. Schattenburg, K.Li et al, J.Vac.Sci.Technol. A11 (1991)

[5] R.Kupka, Y. Chen, F.Rousseaux et al , J.Vac.Sci.Technol. B11 (3) (1993) 667

[6] K.Murata, D.F.Keyser, and C.H.Ting, $J$.Appl.Phys. vol 52 (1982) 5985

[7] K.Murata, J.Appl. Phys. vol 57 (1985) 575

[8] L.E. Ocola, and F.Cerrina, Mat.Res.Soc.Proc. vol 306 (1993) 47

[9] K.Early, M.L. Schattenburg et al. Microelectronic Eng. vol 17 (1992) 149

[10] D.C. Flanders, J.Vac.Sci.Technol. 16 (6) (1979) 1615

[11] R.Dammel, SPIE Press, Vol 11, Bellingham, WA (1993)

[12] L. Blum, Marjorie E. Perkins, and Hua-Yu Liu, J.Vac.Sci.Tecnol. B6 (1988) 2280

[13] F.Gabeli, A.Kucinski et al.Microelectron.Eng. 17 (1992) 203

[14] C.J.Progler, A.C. Chen et al., J.Vac.Sci.Technol. B11(6) (1993) 2888

[15] R. Viswanathan, A. Bright et al., J.Vac.Sci.Tecnol. B11 (1994) 2910

[16] K.Deguchi, J. of Photopolymer Sci. and Technol. vol.6, $\mathrm{n}^{\circ} 4$ (1993) 445

[17] A.M.Haghiri-Gosnet, H.Lafontaine et al.Microelectronic Eng. 23 (1994) 243

[18] T.Hosokawa, T.Kitayama et al., Review of Scientific Instruments, 60 (7) (1989) 1779

[19] N.Takahashi et al., Proc. SPIE 923,(1988) 47

[20] J.P.Silverman, C.N. Archie et al.J.Vac.Sci.Tecnol. B11(6) (1993) 2976

[21] M.N. Wilson, A.I.C. Smith et al. Microelectronics Eng.11 (1990) 225

[22] S.M.Preston, D.W.Peters, and D.N.Tomes, Proc.SPIE vol 1089 (1989) 164

[23] E.A.Dobisz, M.C.Peckerar,et al , Mat. Res.Soc.Symp.Proc. vol 306 (1993) 3

[24] Juan R. Maldonado, SPIE vol 1465 Electron-beam,X-ray, and Ion-Beam Submicrometer Lithographies for Manufacturing (1991) 2

[25] M.Oda, and H.Yoshihara, Mat.Res.Soc.Symp.Proc. vol 306 (1993) 69

[26] A.M.Haghiri-Gosnet, F.Rousseaux, B.Kebabi et al., J.Vac.Sci.Technol. B8 (6) (1990) 1565

[27] M.F.Ravet,A.Gicquet et al., 2nd Intern. Conf. on the Applications of Diamond films and Related Materials (1993) 77.

[28] E.Gat et al., J.Mat.Res., vol 7 (1992) 2478

[29] A.M.Haghiri-Gosnet, F.R.Ladan, et al., J.Vac.Sci.Technol. A 7 (1989) 2663

[30] Y.Chen, R.Kupka, F.Rousseaux et al., Microelectronic Eng.23 (1994) 